\title{
Paid Withdrawal and Optimal Utilization of Rural Homestead
}

\author{
Shang Pengjuan \\ Shanxi University of Finance and Economics, 030000, China
}

Keywords: Homestead withdrawal; compensation targets; compensation scope; financing

\begin{abstract}
With the accelerating progress of towns and agricultural modernization in China, the withdrawal and compensation of rural homestead has become an important issue that influences Chinese urban and rural economy as well as social construction achievements. In this paper, by means of literature method and inductive method, it clears up domestic research on withdrawal and compensation of homestead. Combined with the implementation outcomes of withdrawal and compensation in different areas, it is found that there are some typical problems in the operation of the withdrawal and compensation mechanism of homestead, including the immature withdrawal mechanism, ambiguous compensation measures and weak capital chain. Finally, from aspects of refining the withdrawal procedures, perfecting the compensation mechanism, and expanding the financing channels for the compensation capital of homestead withdrawal, some specific and feasible proposals are put forward.
\end{abstract}

\section{Introduction}

With the gradually broken barriers between China's urban and rural areas, the contradiction between urban and rural land resources utilization is becoming increasingly prominent. On the one hand, under the pressure of 1.8 million mu red line of farmland area, the urban construction land is more and more tense; on the other hand, with large amounts of unused rural houses and constantly expanding homestead, the issue of "hollow village" has become very universal, leading to a serious waste of rural land. In February, 2016, the State Council issued Some Suggestions on Promoting New-type Urbanization, proposing to perfect the circulation mechanism of the right to use homestead, renovate and improve the rural homestead system, and encourage the experimental units to establish a legal voluntary compensation and withdrawal mechanism on rural homestead's right to use for newly settled farmers in cities. Currently, all provinces in China are actively carrying out exploration and practice in the construction of new countryside, which will inevitably involve the withdrawal and compensation of rural homestead. Therefore, to study the withdrawal and compensation mechanism of rural homestead and vitalize the rural construction land in stock is of great significance to remit the contradiction urban construction land, accelerate urban-rural integration and promote the construction of new socialist countryside.

\section{Driving Factors for Withdrawal and Compensation of Rural Homestead}

With the development of urbanization, there is the contradiction between unused homestead and increasing demand for construction land .Accompanied by the rapid development of urbanization, on the one hand, more and more people have transferred their rural registered permanent residence to urban registered permanent residence. Theoretically, the rise in the population of urban residents means the decline of rural residents, reduction of rural settlements and rural construction land. However, in the process of urbanization, rural construction land expands. The primary cause is that the rural homestead in China is collective-owned, and villagers can apply to the collective organization for land free of charge, which leads to villagers' mentality of "suffering no losses" in obtaining homestead. Together with some defects in the land approval system of homestead, some phenomena emerge, such excessive occupation of land, one household with several homesteads and random occupation of farmland. On the other hand, with the accelerating social and economic development as well as urbanization, the increase in per capita income and the growth in the living 
standards have enhanced the public demand for housing and urban public facilities, which further intensifies the contradiction in urban and rural land resource usage.

Due to diversified employment, great changes take place in peasant household's needs for living space .Peasant household's living space changes together with the development of social and economic conditions. Generally, humans' needs for living can be classified according to necessity of survival, requirement for production, demand for development and desire for enjoyment. In China, rural residents' needs are transferring from requirement for production to demand for development, and some rural residents in developed areas are even starting to pursue the desire for enjoyment. This is because great changes have taken place in agricultural production mode due to the continuous improvement in agricultural science and technology and constantly updating of agricultural infrastructure. In this way, the agricultural production time is greatly reduced, leading to the increase of surplus rural labor force, and thus more and more farmers are no longer restricted to agricultural production. In addition, owing to reform in Chinese employment system and household registration system, farmers can adopt diverse patterns of employment. The transformation in making a living influences the choice of rural settlements, which also drives the change in features of their newly built houses.

The severe situation of farmland protection requires of intensive land use.With the substantial increase of rural income, farmers' desire for improving living conditions and building new houses is becoming increasingly stronger. However, influenced by traditional views, rural residents stress inheritance of ancestral property, so they usually will not remove and construct on the old sites. At the same time, because of the relatively weak legal restraints in the countryside, in building new houses, rural residents pay more attention to convenience of traffic and living, phenomena like randomness in house-building, disordered housing distribution, exceeding of residence and blind expanding are hard to restrain. Such unreasonable practices all lead to encroachment of farmland and loss of high-quality farmland. Therefore, under the severe situation of unbroken 1.8 billion mu red line of farmland area, as well as guaranteeing the balance of both quality and quantity of farmland resources, rural residents are required to intensively make use of land resources.

\section{Literature Review}

Due to the integration of land and house, the withdrawal of homestead is defined as the withdrawal of not only the homestead but also the house and other attachments. The compensation for homestead withdrawal refers to reasonably guiding farmers to voluntarily withdraw from the homestead through establishing the attraction mechanism by offering them some compensation.The objects for homestead withdrawal include the complete withdrawal of the right to use homestead due to the change of farmer identity; the vacation of original homestead's right to use caused by land expropriation, comprehensive improvement, natural force majeure and condition improvement etc.; partial withdrawal of homestead's right to use because of the new and existing homesteads' inconformity to national requirement of "one homestead for one household" or the exceeding area.The withdrawal scope of homestead includes both the voluntary withdrawal of the holder of the right to use and the compulsory withdrawal from the original homestead of farmers guided by the government. As to the research on the compensation objects, Hong Yun believes under the principle of " the integration of land and house", the compensation for the attachments to the houses on the homestead have to be given to house owners according to some established standards, and that the non-agricultural people shall not enjoy the compensation fee for land, but they can get certain compensation for the attachments based on their certificate of ownership.

Knowing about farmers' will of homestead withdrawal as well as their interest appeal is of practical significance to boost the homestead withdrawal in a reasonable, orderly and just way. Scholars have adopted Logistic model analysis method,contingent valuation method (CVM)and Probit binary choice model to analyze factors influencing farmers' homestead withdrawal and compensation. Hu Yingen carried out quantitative measurement of its value based on homestead's function and utility to farmers; Chen Linanm did a research based on the homestead's value evolution rule in the withdrawal process, finding that under the condition of a perfectly competitive 
market and equal bargaining ability of buyers and sellers, the homestead withdrawal will produce a balanced compensation price $\frac{P_{n 1}^{2}+P_{N-n 1}^{2}}{2}$, and farmers will obtain the compensation value of homestead withdrawal $\frac{P_{n 1}^{2}+P_{N-n 1}^{2}}{2}$, which can take account of both equity and efficiency.

\section{Summary of Practice in Withdrawal and Compensation Mechanism for Chinese Rural Homestead}

Immature rural homestead withdrawal mechanism .Combined with the homestead withdrawal and compensation mode in various regions across the country, although they all have developed lots of experimental work on rural homestead withdrawal, the regional difference is very significant. Currently, most rural homestead withdrawal in China largely depends on comprehensive improvement of rural land, and the simple homestead withdrawal is relatively rare. As a result, most work on rural homestead withdrawal is still at the exploration stage, and there are no explicit regulations on its regional orientation, withdrawal and compensation scheme, enforcement regulations and specific operation standards. What's more, there is also a lack of relevant operation methods, matching techniques and guiding ideas on rural homestead withdrawal.

Ambiguous measures for the implementation of rural homestead withdrawal and compensation.In China's existing laws, in terms of homestead confiscation, Property Law stipulates basic content for compensation and fundamental principles to guarantee farmers' basic rights and interests, but there is no explicit regulation on the compensation standard, compensation mode as well as system implementation. There is significant regional difference in the layout of China's rural homestead. In some districts, the released homestead withdrawal method is relatively "rough", and in consequence, in the implementation process, the homestead withdrawal and compensation method, as well as farmers' choice of withdrawal and compensation is single, and there is no evaluation system and standard on homestead prices. As Land Management Law has a detailed regulation on the expropriation compensation of land, most districts refer to the land expropriation compensation standards in formulating their collective land compensation standards. However, they seldom considers the compensation standards of homestead starting from the particularity of the homestead, leading to lack of scientificity in value assessment and compensation measurement, thus unable to arouse farmers' enthusiasm of withdrawal.

Capital bottleneck for withdrawal and compensation mechanism caused by weak capital chain .With the continuously decrease of agricultural population, there will be more and more unused rural homestead. Together with the accelerating step of centralized residence in the countryside, homestead far from the centralized residence will withdraw gradually. The withdrawal and compensation projects on rural homestead is characterized by large time span, scattered implementation space and long implementation cycle of return on investment. According to the current homestead withdrawal and compensation process, it can be seen that the government has to invest large amounts of capital. However, in many districts, there are great fiscal difficulties, so overly relying on government funding is difficult to solve the problem of the capital chain for rural homestead withdrawal and compensation. Meanwhile, restricted by the current system, the third-party capital is hard to flexibly participate in the rural homestead withdrawal and compensation, leading to the capital bottleneck in the withdrawal and compensation process.

\section{Suggestions on Perfecting Rural Homestead Withdrawal and Compensation Mechanism}

Perfect the withdrawal procedure of rural homestead .China's current land withdrawal application and the protocol of compensation scheme is roughly consistent with the standard administrative procedure. However, in the legal force of the proper process, there are some defects. Therefore, it is necessary to add and detail a series of key steps on the voluntary withdrawal of homestead, which can not only guarantee farmers' core rights and interests and reflects the legal justice.Refine the application and review procedure for rural homestead withdrawal .Refine the application and review procedure for rural homestead withdrawal. Firstly, the town government 
should deal with propaganda work on rural homestead withdrawal and compensation policies, respect farmers' right to know as homestead users and inform them of the original intention of the policy on homestead withdrawal, and stick to the principle of openness, participation and neutrality in the publicity process. Secondly, in the application process of homestead withdrawal, it is important to abide by the principle of free will. Considering lots of factors influencing farmers' homestead withdrawal, on the one hand, it is necessary to respect the principle of free will, and on the other hand, we have to further perfect relevant measures on withdrawal and compensation so as to moderately satisfy their desire. Lastly, the town government needs to carry out every link of the review content. In this process, besides review according to written materials, it is essential to make necessary field trips and interview related personnel so as to guarantee the land rights and interests of the homestead's real owners. Moreover, the review result should be made public to make sure of information disclosure and justice.

Perfect the compensation mechanism in homestead withdrawal process .To construct the basic framework of rural homestead withdrawal and compensation mechanism, it is important to guarantee both the completeness and the operability of the system. It is necessary to confirm the compensation scope of homestead withdrawal guided by the thought of intensive land use, as well as the payment subject and the paid subjects in rural homestead withdrawal. Confirm compensation scope of homestead withdrawal .Rural homestead refers to the land that farmers obtain to build houses and other attachments according to the law by means of their role in the rural collective economic organization, and farmers have free and indefinite duration of the right to use the homestead. The compensation for homestead withdrawal should include compensation for homestead and compensation for housing demolition. As for the value compensation of homestead, it has to be based on the principle of "one household one homestead", "strictly prohibiting occupation of agricultural land", the illegal homestead will not be compensated, and as to the long-term unused ones, field research has to be done to clarify the ownership for compensation. In compensation for housing demolition, classified compensation should be implemented. Firstly, it involves the value compensation for the houses built on the homestead to be withdrawn in accordance to the compensation requirements; secondly, it involves the compensation for removal and resettlement because of homestead withdrawal; thirdly, it involves the compensation for other economic losses caused by homestead withdrawal. The compensation for the house value should be evaluated specifically by the house value assessment appraisal agency with corresponding qualifications.

Expand financing channels for compensation capital of homestead withdrawal .Compensation capital is a major factor that restricts the effective withdrawal of rural homestead. Thus, it is helpful to perfect the comprehensive market-based financing mode led by the government, and combined with regional features and economic development level, choose proper financing channels to remit the financial pressure of the government in compensation for homestead withdrawal. Expand financing channels for compensation capital of homestead withdrawal .To construct a cycle mechanism on the compensation capital for rural homestead withdrawal is to drive the smooth withdrawal of rural unused homesteads. By means of government advantages, the government-led capital integration can reduce capital operation risks to guarantee the timely funding of the withdrawal capital, but at the same time, the government is likely to be stuck in fiscal difficulties. Under the mature market economy, it is supposed to actively expand the financing channels for marketization of homestead. Firstly, the interest relationship in rural homestead withdrawal has to be clarified, bind the capital by means of various interest relationships, and guarantee the quality and quantity of the capital; secondly, the government has to play its role of regulation in the market-oriented financing mode. Accompanied by industrialization, marketization, scale development and professionalization of land consolidation, the diverse financing can better adapt to the development situation. Comprehensive land financing modes include BOT, TOT, PPP and ABS etc. The comprehensive land financing modes have enriched the subjects of compensation capital sources, making government, financing institutions, rural collective economic organizations ans other market subjects jointly involved in homestead withdrawal, thus providing capital guarantee 
for homestead withdrawal and compensation.

\section{References}

[1] Zhuang Kaiming, Huang Min. Reflection on Perfecting Rural Homestead Withdrawal and Compensation Mechanism [J]. Rural Economy, ,2017(07):13-19.

[2] Zhang Qiuqin, Luo Haibo, Yanjinming, Huang Lushu. Research on Potential Estimation of Rural Homestead Withdrawal in Guizhou- Investigation of Farmers' Will Based on 3 Typical Sample Districts [J]. Guizhou University Journal (Social Sciences), 2014,32(01):46-52.

[3] Yang Lixia, Zhu Congmou, Yuan Shaofeng, Li Shengnan. Analysis of Farmers' Will of Homestead Withdrawal and Welfare Change Based on Supply-side Reform-Take Yiwu City of Zhejiang Province as an Example [J]. China Land Science,2018,32(01):35-41. 